\title{
The use of gabapentin enacarbil in the treatment of restless legs syndrome
}

\author{
Toby C. Yaltho and William G. Ondo
}

\begin{abstract}
Restless legs syndrome (RLS) is a common sleep-related neurological disorder that is characterized by the urge to move, worsening at rest, improvement with activity, and worsening in the evening and night. Dopamine agonists are usually the first-line therapy. Other agents including benzodiazepines, narcotics, and anticonvulsants have been used to treat RLS. Gabapentin has been shown to improve RLS in a small number of clinical studies, but is limited by its short half-life and variable bioavailability. Gabapentin enacarbil is a novel prodrug of gabapentin designed to overcome these pharmacokinetic limitations. In vitro and in vivo studies have demonstrated that gabapentin enacarbil has improved absorption, bioavailability and pharmacokinetics compared with gabapentin. Phase II and III studies have demonstrated that gabapentin enacarbil is generally well tolerated and is useful in the treatment of RLS.
\end{abstract}

Keywords: restless legs syndrome, gabapentin, gabapentin enacarbil, treatment

\section{Background}

Restless legs syndrome (RLS) is a movement disorder that affects between $5 \%$ and $10 \%$ of adults [Hening et al. 2004; Phillips et al. 2000; Lavigne and Montplaisir, 1994]. It is clinically defined by the presence of four criteria: (1) an urge to move the limbs with or without sensations, (2) worsening at rest, (3) improvement with activity, and (4) worsening in the evening or night [Allen et al. 2003]. Patients use a variety of terms to describe these abnormal sensations (e.g. crawling, tingling, cramping, creeping, pulling, electric shock, itching). Features typical for RLS include the tendency for symptoms to gradually worsen with age, a positive family history of RLS, and periodic limb movements of sleep (PLMS) [Ondo, 2009].

The majority of patients have primary (idiopathic) RLS. Secondary (symptomatic) causes of RLS include iron deficiency, peripheral neuropathy, uremia, sleep apnea, Parkinson's disease, multiple sclerosis, pregnancy, and medications (antidepressants, antihistamines and dopamine antagonists). A family history of RLS can be found in $40-60 \%$ of patients, although this is often not reported by the patient [Ondo and Jankovic, 1996]. Linkage studies in
RLS families have revealed numerous loci but no causally related sequence variants in individual families. Four genes conferring risk in population studies have also been identified [Schormair et al. 2008; Winkelmann et al. 2007].

Patients with mild symptoms do not require treatment. Previous studies estimate that approximately $2-3 \%$ of the population have RLS that is severe enough to warrant treatment [Allen et al. 2005; Hening et al. 2004]. There are multiple therapeutic options for the treatment of RLS. Dopamine agonists (pramipexole and ropinirole) are generally considered first-line agents for treatment of moderate-to-severe RLS. Polysomnogram studies of dopamine agonists consistently show dramatic improvement in PLMS, but neither ropinirole nor pramipexole have demonstrated improved sleep architecture [Partinen et al. 2006; Bliwise et al. 2005; Allen et al. 2004]. Adverse effects of dopamine agonists may limit their use. Some patients report augmentation of RLS symptoms with long-term dopaminergic treatment. Augmentation results in an earlier onset, and possible intensification of symptoms. Short-lasting dopamine agonists may contribute to recurrence of early-morning RLS symptoms (rebound). Other medications
Ther Adv Neurol Disord (2010) 3(5) 269-275 DOI: $10.1177 /$ 1756285610378059

(C) The Author(s), 2010. Reprints and permissions: http://www.sagepub.co.uk/ journalsPermissions.nav

Correspondence to: William G. Ondo, MD Professor of Neurology, Parkinson's Disease Center and Movement Disorders Clinic

Department of Neurology, Baylor College of Medicine, 6550 Fannin, Suite 1801, Houston, TX 77030, USA wondolabcm.edu Toby C. Yaltho, MD Parkinson's Disease Center and Movement Disorders Clinic, Department of Neurology, Baylor College of Medicine, Houston, TX, USA 
used include levodopa, narcotics, benzodiazepines, and anticonvulsant medications such as carbamazepine, pregabalin, and gabapentin.

\section{Gabapentin}

Gabapentin was initially approved as adjunctive treatment for epilepsy in the United States in 1994. In 2002 it was approved for the treatment of postherpetic neuralgia. Gabapentin (1-(aminomethyl)-cyclohexaneacetic acid) is a gammaaminobutyric acid (GABA) analog that interacts with the $\alpha 2 \delta-1$ subunit of the voltage-dependent calcium channel, leading to a reduction in $\mathrm{Ca}^{2+}$ influx into presynaptic nerve terminals and inhibition of the release of excitatory neurotransmitters [Adler et al. 1997; Gee et al. 1996]. Gabapentin is absorbed by low-capacity solute transporters located in the small intestine that become saturated at therapeutic doses. As a result, the bioavailability of gabapentin is not dose proportional. Bioavailability decreases as the dose is increased. The bioavailability is $60 \%$ at $300 \mathrm{mg}$ and $\leq 40 \%$ at doses of $1600-4800 \mathrm{mg}$ [McLean, 1995]. Gabapentin is eliminated unchanged by renal excretion and has a half-life of 5-7 h. The short half-life and its variable bioavailability limit its use. Clinical studies have demonstrated improvement in RLS in patients treated with gabapentin. An open-label study demonstrated that gabapentin and ropinirole provide a similarly well-tolerated and effective treatment of PLMS and RLS [Happe et al. 2003]. Gabapentin has been shown to improve sleep quality in patients with RLS and significantly reduce the number of PLMS, PLMS arousal index, and arousal index [Happe et al. 2001]. An average gabapentin dose of $1855 \mathrm{mg}$ improved the mean IRLS total score in a 6-week crossover study [Garcia-Borreguero et al. 2002]. There was also improvement in total sleep time, sleep efficiency, and slow wave sleep, as well as a decrease in sleep stage 1 .

\section{Gabapentin enacarbil}

Gabapentin enacarbil (XP13512/GSK1838262 $(( \pm)-1-([\alpha$-isobutanoyloxyethoxy) carbonyl]-aminomethyl1)-1-cyclohexane acetic acid) is a novel transported prodrug of gabapentin designed to overcome the pharmacokinetic limitations of gabapentin. Gabapentin enacarbil is absorbed by high-capacity nutrient transporters that are broadly distributed in the gastrointestinal system and then undergoes rapid hydrolysis by nonspecific esterases to gabapentin. Hydrolysis of gabapentin enacarbil yields gabapentin and equimolar amounts of isobutyric acid, acetaldehyde, and carbon dioxide. These products were selected to preserve the safety profile of the parent drug. The pathway for absorption is not saturated at clinically useful doses providing dose-proportional absorption and improved bioavailability [Merlino et al. 2009; Cundy et al. 2004b].

In vitro studies were performed to evaluate the release of gabapentin from gabapentin enacarbil in various tissues and buffers. The conversion of gabapentin enacarbil to gabapentin after incubation for $1 \mathrm{~h}$ at $37^{\circ} \mathrm{C}$ in pancreatin and Caco-2 cell homogenate, rat plasma, human plasma, rat liver, and human liver was $42 \%, 75 \%, 25 \%, 5 \%, 71 \%$, and $81 \%$, respectively. Gabapentin enacarbil did not demonstrate any significant inhibition of the major isoforms of P450. Over the concentration range $5-100 \mu \mathrm{Mk}$, gabapentin enacarbil was $78-87 \%$ bound to human serum albumin.

In vitro transport studies demonstrated $\mathrm{pH}$-dependent passive permeability across artificial lipid membranes. Gabapentin enacarbil is recognized as a substrate by high-capacity nutrient transporters, monocarboxylase transport type 1 (MCT-1) and sodium-dependent multivitamin transporter (SMVT), which are widely distributed in the intestine.

In animal studies, the oral bioavailability of gabapentin from gabapentin enacarbil was consistently high in both rats and monkeys $(64.9-71.2 \%$ and $60.1-93.5 \%$, respectively). There was a 17 -fold increase in absorption in rats and a 34-fold absorption increase in monkeys of intracolonic gabapentin enacarbil compared with intracolonic gabapentin. Following oral dosing of ${ }^{13} \mathrm{C}$-labeled gabapentin enacarbil to rats, radioactivity was distributed to most tissues, with the highest concentration in the pancreas. Greater than $95 \%$ of the radioactive dose was recovered in the urine in $24 \mathrm{~h}$ and less than $1 \%$ was recovered in the feces. Radioactive flow studies did not detect intact gabapentin enacarbil in the urine, indicating effective conversion to gabapentin [Cundy et al. 2004a].

\section{Phase I trials}

The pharmacokinetics of immediate-release (IR) and extended-release (XR) formulations of gabapentin enacarbil were compared with gabapentin in four studies of healthy volunteers [Cundy et al. 2008]. In the XP006 trial, subjects received 
single doses of gabapentin enacarbil IR (350, $700,1400,2100$, or $2800 \mathrm{mg} ; n=40$ ) or placebo $(n=10)$. After 1 week, all subjects received approximately equimolar doses of gabapentin $(200,400,800,1200$, and $1400 \mathrm{mg})$ or placebo. The $T_{\max }$ values ranged from 2.06 to $2.63 \mathrm{~h}$ for gabapentin enacarbil compared with from 2.80 to $3.30 \mathrm{~h}$ for gabapentin. The $t_{1 / 2}$ ranged from 4.38 to $5.47 \mathrm{~h}$ with gabapentin enacarbil IR and from 5.40 to $9.26 \mathrm{~h}$ with gabapentin. Exposure to gabapentin from the prodrug was dose proportional, but it was not dose proportional after administration of oral gabapentin. The bioavailablity after administration of the prodrug $(82.9 \%$ at $350 \mathrm{mg}$ and $72.3 \%$ at $2100 \mathrm{mg}$ ) was higher compared with approximately equimolar dose of gabapentin $(65.2 \%$ at $200 \mathrm{mg}$ and $26.5 \%$ at $1400 \mathrm{mg}$ ).

In the XP018 trial, subjects received twice-daily doses of gabapentin enacarbil IR (350, 700, 1400 , or $2100 \mathrm{mg} ; n=30)$ or placebo $(n=8)$ for 7 days. The $T_{\max }$ values ranged from 1.56 to $1.92 \mathrm{~h}$ and the $t_{1 / 2}$ was 4.57 to $5.17 \mathrm{~h}$. The bioavailability of gabapentin from the prodrug was consistently high $(\geq 74 \%)$ across the dose range.

In the randomized, crossover, clinical trial XP022, subjects received $1200 \mathrm{mg}$ gabapentin enacarbil XR with $(n=11)$ or without $(n=12)$ food or $600 \mathrm{mg}$ of gabapentin without food $(n=10)$. The $T_{\max }$ was shorter in the subjects receiving gabapentin (2.73 hours) than in the groups receiving gabapentin enacarbil (8.40 and $5.08 \mathrm{~h}$ with or without food, respectively). The bioavailability of gabapentin was higher in subjects receiving gabapentin enacarbil XR with or without food $(74.5 \%$ and $46.5 \%$, respectively) compared with oral dosing of gabapentin without food $(36.6 \%)$.

Trial XP044 was a randomized, crossover study of single doses of gabapentin enacarbil XR (300, 600 , or $1200 \mathrm{mg} ; n=36$ ) in the fasted and fed state. Exposure to gabapentin was dose proportional over the dose range studied. The $T_{\max }$ was delayed and the bioavailability was increased in the presence of food. The bioavailability was approximately $60 \%$ in fasted subjects and $80 \%$ in fed subjects.

An open-label, crossover study (XP087) to assess the effect of food on the pharmacokinetics of gabapentin enacarbil was conducted in
12 healthy subjects. Each subject received $1200 \mathrm{mg}$ of gabapentin enacarbil daily in four conditions using a four-period crossover design, with at least a 5-day washout between treatments (fasting, low-fat $200-300 \mathrm{kcal}$, moderate-fat $500-600 \mathrm{kcal}$, or high-fat $1000 \mathrm{kcal})$. The exposure and bioavailability of gabapentin from gabapentin enacarbil were increased in the presence of food (bioavailability was $42.0 \%$ in fasting patients, and $64.3 \%, 64.9 \%$, and $76.1 \%$ in the low-, moderate-, and high-fat conditions, respectively) [Lal et al. 2008].

Another double-blind, randomized, placebo-controlled, crossover study (XP069) following single daily supratherapeutic doses of gabapentin enacarbil XR $(2400,3600,4800$, and $6000 \mathrm{mg})$ in healthy volunteers $(n=32)$ demonstrated that the prodrug was well absorbed and converted rapidly into gabapentin. Levels of the intact prodrug were low and transient. Gabapentin enacarbil XR provided dose-proportional exposure of gabapentin over the dose range $2400-6000 \mathrm{mg}$ (1250-3125 mg equivalent gabapentin) [Lal et al. 2009].

\section{Phase II clinical trials for RLS}

In a randomized, double-blind, placebo-controlled, crossover trial (XP021) in moderate-tosevere primary RLS, treatment-naïve subjects received $1800 \mathrm{mg} /$ day of gabapentin enacarbil $(600 \mathrm{mg}$ at $05: 00$ and $1200 \mathrm{mg} 1 \mathrm{~h}$ before bedtime) or placebo with a 7-day washout between each 14-day treatment. The primary endpoint was the change from baseline to day 14 on the International Restless Legs Scale (IRLS), a 10-question, 0-40 scale used in most major RLS therapeutic trials. The secondary endpoints were the change from baseline IRLS at day 7, patient- and investigator-rated Clinical Global Impression-Improvement (CGI-I) scale on days 8 and 15, subjective measures of sleep, suggested immobilization test (SIT), and polysomnogram. The mean change in baseline IRLS total score at day 14 was significantly greater following treatment with gabapentin enacarbil compared with placebo ( -12.1 versus -1.9$)$. Improvement in IRLS total score was seen at day $7(-11.7$ with gabapentin enacarbil compared with -3.7 with placebo). The percentage of subjects treated with gabapentin enacarbil that reported symptoms as 'much improved' or 'very much improved' at day 14 was $85.3 \%$, compared with $14.7 \%$ for placebo. Subjects treated with gabapentin enacarbil had improvement in 
CGI-I responses, sleep quality, amount of time RLS symptoms were present, severity of RLS symptoms, number of hours awake per night due to RLS symptoms, and number of awakenings per night due to RLS, when compared with placebo. Polysomnogram demonstrated that gabapentin enacarbil improved sleep architecture, including shortening stage 1 sleep and extending time spent in slow-wave sleep [Kushida et al. 2009b].

A phase 2b, double-blind, randomized, controlled trial (XP045) compared the efficacy of gabapentin enacarbil once daily versus placebo in treatment-naïve patients with moderate-tosevere primary RLS. Subjects were randomized to receive gabapentin enacarbil 600 or $1200 \mathrm{mg}$ or matching placebo at $5 \mathrm{pm}$ with food for 14 days $(n=95)$. The primary endpoint was the mean change from baseline IRLS total score at day 14 . The secondary endpoints were the mean change from baseline IRLS total score at day 7 of treatment, outcomes on the patient- and investigator-rated CGI-I scale at day 14, subject-rated sleep questionnaire, mood assessment questionnaire, subject-assessed RLS pain questionnaire, and 24 hour diary recording the presence and severity of RLS symptoms at baseline and on days 7 and 14. The mean change from baseline IRLS score at day 14 was significantly greater with gabapentin enacarbil at $1200 \mathrm{mg}$ compared with placebo ( -16.1 , compared with -8.9 with placebo). In addition, gabapentin enacarbil at $1200 \mathrm{mg}$, improved RLS symptoms at day 7 (-14.2, compared with -7.8 with placebo). Compared with placebo, patients receiving gabapentin enacarbil $1200 \mathrm{mg}$ had improvement in CGI-I responses, overall sleep quality, number of nights with RLS symptoms, number of awakenings during the night due to RLS symptoms, number of hours awake per night due to RLS symptoms, mood assessment, median time to onset of first symptoms, duration of RLS symptoms, and severity of RLS symptoms. Treatment with $600 \mathrm{mg}$ of gabapentin enacarbil did not demonstrate improvement over placebo [Walters et al. 2009].

\section{Phase III clinical trials}

In a multicenter, randomized, double-blind, placebo-controlled trial (XP052), patients with moderate-to-severe primary RLS received gabapentin enacarbil $1200 \mathrm{mg}$ or placebo once daily at $17: 00$ with food for 12 weeks $(n=220)$ [Kushida et al. 2009a]. Prior RLS treatment was discontinued at least 2 weeks prior to baseline assessment.
The coprimary endpoints were the mean change from baseline IRLS total score at 12 weeks and the percentage rated as responders on the investigator-rated CGI-I scale at 12 weeks. The mean change from baseline IRLS total score at week 12 was greater with gabapentin enacarbil compared with placebo ( -13.2 versus -8.8$)$. At week 12 , more patients treated with gabapentin enacarbil $(76.1 \%)$ were rated by investigators as responders compared with placebo (38.9\%). Gabapentin enacarbil was superior to placebo for both coprimary endpoints by week 1, and this was maintained through week 12 .

In another phase III, multicenter, randomized, double-blind, placebo-controlled, parallel-group study (XP053), subjects with moderate-tosevere primary RLS received gabapentin enacarbil $600 \mathrm{mg}, 1200 \mathrm{mg}$, or placebo daily at $5 \mathrm{pm}$ for 12 weeks $(n=321)$. Prior treatment for RLS was not stated. The coprimary outcome measures were the mean change in IRLS total score from baseline to 12 weeks and the proportion of responders rated as 'much improved' or 'very much improved' on the CGI-I scale at week 12. There was improvement in both the IRLS total score and CGI-I scale at week 12 for both doses compared with placebo. The improvement in IRLS total score was -13.8 and -13.0 for the 600 and $1200 \mathrm{mg}$ groups, respectively, compared with -9.8 with placebo. Significantly more subjects receiving gabapentin enacarbil $600 \mathrm{mg}$ $(72.8 \%)$ and $1200 \mathrm{mg}(77.5 \%)$ were rated as responders on the investigator-rated CGI-I scale compared with placebo [Lee et al. 2009].

A third phase III, multicenter, randomized, placebo-controlled trial (XP060) was conducted to evaluate the efficacy and long-term tolerability of gabapentin enacarbil in RLS $(n=327)$ [Bogan et al. 2009]. Subjects were not receiving prior RLS treatment or discontinued treatment prior to or within the month before starting study medication. In the initial 24-week, single-blind treatment phase, subjects received gabapentin enacarbil $1200 \mathrm{mg}$ once daily or placebo at $17: 00$ with food. A total of 221 subjects completed the initial phase, and 194 (88\%) were considered responders with an IRLS total score reduction of $\geq 6$ points and 'much improved' or 'very much improved' on the CGI-I scale. These 194 patients then entered into a 12-week, double-blind, parallel-group phase where they received (1) gabapentin enacarbil $1200 \mathrm{mg} /$ day for 12 weeks or (2) gabapentin $600 \mathrm{mg} /$ day for 
2 weeks followed by placebo for 10 weeks. The primary endpoint was the proportion of subjects who relapsed during the double-blind phase defined as an increase of $\geq 6$ points in IRLS total score, a rating of 'much worse' or 'very much worse' on the investigator-rated CGI-I scale, or withdrawal due to lack of efficacy. A statistically significant lower percentage of gabapentin enacarbil treated subjects relapsed during the double-blind phase compared with placebo ( $9.4 \%$ versus $22.7 \%$ ).

\section{Discussion}

Gabapentin enacarbil is a prodrug of gabapentin, designed to be recognized as a substrate by two high-capacity nutrient transporters (MCT-1 and SMVT) distributed throughout the intestine. Gabapentin enacarbil is stable at physiological $\mathrm{pH}$ and rapidly converted into gabapentin. Active transport, passive absorption, and rapid hydrolysis lead to efficient bioavailability without the limitation of saturation observed with gabapentin.

Administration of gabapentin enacarbil with food enhances gabapentin exposure regardless of the fat content of food. Clinical studies have demonstrated that concentrations of the intact prodrug in blood did not exceed $2 \%$, suggesting that gabapentin enacarbil is efficiently converted into gabapentin [Cundy et al. 2008]. Dose-proportional exposure of gabapentin enacarbil up to $6000 \mathrm{mg}$ allows reduced dosing frequency compared with gabapentin. Improved bioavailability and dosedependent exposure allows for once-daily dosing.

Multiple studies of gabapentin enacarbil demonstrate efficacy over placebo in patients with RLS. Improvement in RLS symptoms was observed as early as 7 days. Three studies demonstrated that a dose of $1200 \mathrm{mg} /$ day gabapentin enacarbil significantly reduced IRLS total score and improved CGI-I compared with placebo. One study did not show efficacy of $600 \mathrm{mg}$ but two others did show efficacy at that dose. Overall these results are similar to those seen with dopamine agonists. Unlike dopamine agonists, improvement in sleep architecture manifested by increased slow-wave sleep was also reported. Periodic limb movements improved but to a lesser degree than seen in the dopamine agonist studies [Allen et al. 2004; Montplaisir et al. 1999]. These findings are consistent with the results of a recent study of gabapentin versus ropinirole for RLS which demonstrated improvement in objective and subjective sleep and awakening quality with gabapentin compared with a reduction in periodic limb movement measures with ropinirole [Saletu et al. 2010].

Gabapentin enacarbil was designed to overcome the pharmacokinetic limitations of gabapentin. Improved bioavailability and dose-dependent exposure allows for once daily dosing. Formulations of gabapentin enacarbil have been well tolerated at doses up to $6000 \mathrm{mg}$ and adverse effects were generally reported as mild in intensity. The most frequent adverse effects in clinical trials were dizziness, somnolence, and headaches consistent with the known side-effect profile of oral gabapentin. One seizure reported during drug withdrawal was of unclear clinical significance [Bogan et al. 2009]. Augmentation was not reported, but most studies were of short duration.

Gabapentin enacarbil is a novel prodrug that is an effective treatment alternative in RLS. Future useful studies in RLS would include direct comparisons with gabapentin and pregabalin, comparisons with dopamine agonists, long-term open-label studies to assess for tolerability and augmentation, and studies in RLS associated with specific diseases, especially uremia.

\section{Funding}

This research received no specific grant from any funding agency in the public, commercial, or notfor-profit sectors

\section{Conflict of interest statement}

WGO has received fees via a speaker bureau for Lundbeck, GlaxoSmithKline, Teva Neuroscience, Boehringer Ingelheim, and Allergen. TCY has no conflicts of interest to declare.

\section{References}

Adler, C.H., Sethi, K.D., Hauser, R.A., Davis, T.L., Hammerstad, J.P., Bertoni, J. et al. (1997) Ropinirole for the treatment of early Parkinson's disease. The Ropinirole Study Group. Neurology 49: 393-399.

Allen, R., Becker, P.M., Bogan, R., Schmidt, M., Kushida, C.A., Fry, J.M. et al. (2004) Ropinirole decreases periodic leg movements and improves sleep parameters in patients with restless legs syndrome. Sleep 27: 907-914.

Allen, R.P., Picchietti, D., Hening, W.A., Trenkwalder, C., Walters, A.S. and Montplaisi, J. (2003) Restless legs syndrome: diagnostic criteria, special considerations, and epidemiology. A report from the restless legs syndrome diagnosis and epidemiology workshop 
at the National Institutes of Health. Sleep Med 4: $101-119$

Allen, R.P., Walters, A.S., Montplaisir, J., Hening, W., Myers, A., Bell, T.J. et al. (2005) Restless legs syndrome prevalence and impact: REST general population study. Arch Intern Med 165: 1286-1292.

Bliwise, D.L., Freeman, A., Ingram, C.D., Rye, D.B., Chakravorty, S. and Watts, R.L. (2005) Randomized, double-blind, placebo-controlled, short-term trial of ropinirole in restless legs syndrome. Sleep Med 6: $141-147$.

Bogan, R., Cramer Bornemann, M.A., Kushida, C.A., Tran, P. and Barrett, R.W. (2009) A randomized, double-blind, placebo-controlled study to assess the efficacy and safety of gabapentin enacarbil in subjects with restless legs syndrome. American Academy of Neurology 2009-61st Annual Meeting, April 2009.

Cundy, K.C., Annamalai, T., Bu, L., De Vera, J., Estrela, J., Luo, W. et al. (2004a) XP13512 [(+/-)-1([(alpha-isobutanoyloxyethoxy)carbonyl] aminomethyl)-1-cyclohexane acetic acid], a novel gabapentin prodrug: II. Improved oral bioavailability, dose proportionality, and colonic absorption compared with gabapentin in rats and monkeys. $\mathcal{F}$ Pharmacol Exp Ther 311: 324-333.

Cundy, K.C., Branch, R., Chernov-Rogan, T., Dias, T., Estrada, T., Hold, K. et al. (2004b) XP13512 [(+/-)-1-([(alpha-isobutanoyloxyethoxy)carbonyl] aminomethyl)-1-cyclohexane acetic acid], a novel gabapentin prodrug: I. Design, synthesis, enzymatic conversion to gabapentin, and transport by intestinal solute transporters. F Pharmacol Exp Ther 311: 315-323.

Cundy, K.C., Sastry, S., Luo, W., Zou, J., Moors, T.L. and Canafax, D.M. (2008) Clinical pharmacokinetics of XP13512, a novel transported prodrug of gabapentin. F Clin Pharmacol 48: 1378-1388.

Garcia-Borreguero, D., Larrosa, O., de la Llave, Y., Verger, K., Masramon, X. and Hernandez, G. (2002) Treatment of restless legs syndrome with gabapentin: a double-blind, cross-over study. Neurology 59: 1573-1579.

Gee, N.S., Brown, J.P., Dissanayake, V.U., Offord, J., Thurlow, R. and Woodruff, G.N. (1996) The novel anticonvulsant drug, gabapentin (Neurontin), binds to the alpha2delta subunit of a calcium channel. $\mathcal{F}$ Biol Chem 271: 5768-5776.

Happe, S., Klosch, G., Saletu, B. and Zeitlhofer, J. (2001) Treatment of idiopathic restless legs syndrome (RLS) with gabapentin. Neurology 57: $1717-1719$.

Happe, S., Sauter, C., Klosch, G., Saletu, B. and Zeitlhofer, J. (2003) Gabapentin versus ropinirole in the treatment of idiopathic restless legs syndrome. Neuropsychobiology 48: 82-86.

Hening, W., Walters, A.S., Allen, R.P., Montplaisir, J., Myers, A. and Ferini-Strambi, L. (2004) Impact, diagnosis and treatment of restless legs syndrome
(RLS) in a primary care population: the REST (RLS epidemiology, symptoms, and treatment) primary care study. Sleep Med 5: 237-246.

Kushida, C.A., Becker, P.M., Ellenbogen, A.L., Canafax, D.M. and Barrett, R.W. (2009a)

Randomized, double-blind, placebo-controlled study of XP13512/GSK1838262 in patients with RLS. Neurology 72: 439-446.

Kushida, C.A., Walters, A.S., Becker, P., Thein, S.G., Perkins, A.T., Roth, T. et al. (2009b) A randomized, double-blind, placebo-controlled, crossover study of XP13512/GSK1838262 in the treatment of patients with primary restless legs syndrome. Sleep 32: 159-168.

Lal, R., Sukbuntherng, J., Luo, W., Chen, D., Vu, A., Tovera, J. et al. (2009) Pharmacokinetics and tolerability of single escalating doses of gabapentin enacarbil: a randomized-sequence, double-blind, placebo-controlled crossover study in healthy volunteers. Clin Ther 31: 1776-1786.

Lal, R., Sukbuntherng, J., Luo, W., Huff, J. and Cundy, K.C. (2008) Effect of food on the clinical pharmacokinetics of XP13512 in healthy volunteers. Annual Meeting of the Associated Professional Sleep Societies, 7-12 June 2008, Abstract P136.

Lavigne, G.J. and Montplaisir, J.Y. (1994) Restless legs syndrome and sleep bruxism: prevalence and association among Canadians. Sleep 17: 739-743.

Lee, D.O., Ziman, R.B., Perkins, A.T., Poceta, J.S., Walters, A.S. and Barrett, R.W. (2009) A randomized, double-blind, placebo-controlled study to assess the efficacy and safety of gabapentin enacarbil in subjects with restless legs syndrome. American Academy of Neurology 2009-61st Annual Meeting, April 2009.

McLean, M.J. (1995) Gabapentin. Epilepsia 36(Suppl 2): S73-S86.

Merlino, G., Serafini, A., Young, J.J., Robiony, F., Gigli, G.L. and Valente, M. (2009) Gabapentin enacarbil, a gabapentin prodrug for the treatment of the neurological symptoms associated with disorders such as restless legs syndrome. Curr Opin Investig Drugs 10: $91-102$.

Montplaisir, J., Nicolas, A., Denesle, R. and GomezMancilla, B. (1999) Restless legs syndrome improved by pramipexole: a double-blind randomized trial. Neurology 52: 938-943.

Ondo, W. and Jankovic, J. (1996) Restless legs syndrome: clinicoetiologic correlates. Neurology 47: 1435-1441.

Ondo, W.G. (2009) Restless legs syndrome. Neurol Clin 27: 779-799, vii.

Partinen, M., Hirvonen, K., Jama, L., Alakuijala, A., Hublin, C., Tamminen, I. et al. (2006) Efficacy and safety of pramipexole in idiopathic restless legs syndrome: a polysomnographic dose-finding study-the PRELUDE study. Sleep Med 7: 407-417. 
Phillips, B., Young, T., Finn, L., Asher, K., Hening, W.A. and Purvis, C. (2000) Epidemiology of restless legs symptoms in adults. Arch Intern Med 160: 2137-2141.

Saletu, M., Anderer, P., Saletu-Zyhlarz, G.M., Parapatics, S., Gruber, G., Nia, S. et al. (2010) Comparative placebo-controlled polysomnographic and psychometric studies on the acute effects of gabapentin versus ropinirole in restless legs syndrome. f Neural Transm 117: 463-473.

Schormair, B., Kemlink, D., Roeske, D., Eckstein, G., Xiong, L., Lichtner, P. et al. (2008) PTPRD (protein tyrosine phosphatase receptor type delta) is associated with restless legs syndrome. Nat Genet 40: 946-948.

Walters, A.S., Ondo, W.G., Kushida, C.A., Becker, P.M., Ellenbogen, A.L., Canafax, D.M. et al. (2009) Gabapentin enacarbil in restless legs syndrome: a phase $2 \mathrm{~b}, 2$-week, randomized, double-blind, placebocontrolled trial. Clin Neuropharmacol 32: 311-320.

Winkelmann, J., Schormair, B., Lichtner, P., Ripke, S., Xiong, L., Jalilzadeh, S. et al. (2007) Genome-wide association study of restless legs syndrome identifies common variants in three genomic regions. Nat Genet Visit SAGE journals online http://tan.sagepub.com 39: 1000-1006. 